\title{
Comparative Study Between Fuzzy and Sliding Mode Control Based on a BDFIG
}

\author{
Laid Ouada, B. Sebti \\ Electrical Engineering Department,University of Batna 2, Batna, ALGERIA \\ e-mail:ouada.laid@gmail.com
}

\begin{abstract}
Brushless doubly fed induction (BDFIG) is one of the best solutions of the previous research efforts about wind-power converter, which is represented by the absence of a brush gear and less maintenance cost, especially in the harsh regions. This task presents a comparative evaluation between a sliding mode and Fuzzy control. It demonstrates also the robustness of these two regulators against supply voltage and load disturbances. Furthermore, we have shown the undesirable phenomenon of oscillations having a finite frequency and amplitude, which is known as 'chattering' resulted from a sliding mode control which is based on Lyapunov approach theorem. The control of the system and BDFIG are both integrated in variable speed wind energy conversion. The performances of these control systems have been tested and analyzed in Matlab Simulink.
\end{abstract}

Keywords: Brushless doubly-fed induction generator, Neuro-Fuzzy Sliding mode control Received: 12/11/2019 - Accepted: 15/12/2019

\begin{tabular}{llll} 
NOMENCLATURE & & & \\
\hline Wind Turbine & & \\
\hline$V_{s p}^{q}, V_{s p}^{d}, V_{s c}^{q}, V_{s c}^{q}$ & Stator and rotor d-q reference frame voltages & $C_{e m}$ & Rotor winding resistances \\
$I_{s p}^{q}, I_{s p}^{d}, I_{s c}^{q}, I_{s c}^{q}$ & Stator and rotor d-q reference frame currents & $P_{s p}$ & Total cyclic stators inductances \\
$\psi_{s p}^{q}, \psi_{s p}^{d}, \psi_{s c}^{q}, \psi_{s c}^{q}, \psi_{r}^{q}, \psi_{r}^{d}$ & Stator and rotor d-q reference frame flux & $Q_{s p}$ & Number of pole pairs for power control \\
\cline { 2 - 3 }$R_{s p}, R_{s c}$ & Stator winding resistances & Abbreviations \\
\cline { 2 - 3 }$L_{r}$ & Total cyclic rotor inductance & DFIG & Doubly feed induction \\
$L_{m p}, L_{m c}$ & Magnetizing inductances & BFFIG & Brushless Doubly Fed Induction \\
$w_{c}, w_{p}, w_{n}$ & Stators synchronous angular frequency & DFIG & Doubly Fed Induvtion Generator \\
$R_{r}$ & Number of pole pairs for power control & BDFIG & Doubly Fed Induvtion Generator \\
$L_{s p}, L_{s c}$ & Electromagnetic torque & ANN & Artificiel neural network \\
$p_{c}$ & Active of stator powers & SMC & Sliding mode Control \\
$p_{p}$ & Reactive of stator powers & NF - SMC & Neuro Fuzzy Sliding mode Control \\
\hline
\end{tabular}




\section{Introduction}

During the last years, there was a considerable exploitation of wind power energy which was expected to supply $5 \%$ of electrical global power during 2016, it suggests an approximation of $25 \%$ by the end of 2020 [1].

Undoubtedly, the doubly fed induction (DFIG) has become the most useful model in wind power application. But because of the presence of slip ring and brushes which requires more control and maintenance; therefore, it limits its application in harsh environment $[2,3]$. In this way, the emerging of BFFIG has made up for many drawbacks of usual electric machines, as being Brushless and without slip ring.

Brushless doubly fed induction generator (BDFIG) includes a stator which incorporates two sets of three phase windingwith different number of poles. The first is connected directly to the electrical grid, named the power winding (PW). The second is laid through a bidirectional converter to the grid, called control winding (CW) $[3,4]$.

The rotor of BDFIG consists of specially designed nested loops which may be connected or separated from each other aspresented in the following figure 1.

The Fuzzy logic control has been considered as one of the most successful expert systems which has been widely applied in control applications. [5]. As it doesn't require a detailed mathematical model, it just uses the knowledge of the total operation of the system to build its based rule.

The Sliding mode control strategy is determined by the sum of two control laws: switching and equivalent It achieves robust control by adding a discontinuous control law $[6,7]$.Signal across the sliding surface, satisfying the sliding condition. Nevertheless, this type of control has an usual disadvantage, known by the "chattering" phenomenon due to the discontinuous control action [8].

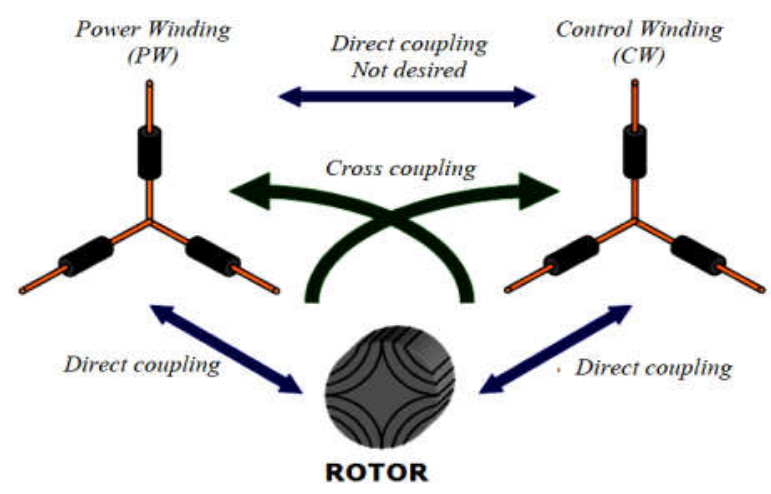

Figure. 1. Configuration of a BDFIG

\section{Modeling of the Brushless Doubly Fed Induction Generator}

The general relationships between these amounts as well as the electrical speed of the rotor for the $50 \mathrm{~Hz}$ system is

$$
\left\{\begin{array}{l}
\omega_{p}=2 \pi 50 \\
\omega_{r}=\omega_{p}-\omega_{n} p_{p} \\
\omega_{c}=\omega_{p}-\left(p_{p}+p_{c}\right) \omega_{n}
\end{array}\right.
$$

The expressions for states' and rotor flux connections are given by the following equation:

$$
\left\{\begin{array}{l}
\psi_{s p}^{q}=L_{s p} I_{s p}^{q}+L_{m p} I_{r}^{q} \\
\psi_{s p}^{d}=L_{s p} I_{s p}^{d}+L_{m p} I_{r}^{d} \\
\psi_{r}^{q}=L_{m p} I_{s p}^{q}+L_{r} I_{r}^{q}+L_{m c} I_{s c}^{q} \\
\psi_{s p}^{d}=L_{m p} I_{s p}^{q}+L_{r} I_{r}^{q}+L_{m c} I_{s c}^{q} \\
\psi_{s c}^{q}=L_{s c} I_{s c}^{q}+L_{m c} I_{r}^{q} \\
\psi_{s p}^{d}=L_{s c} I_{s p}^{d}+L_{m c} I_{r}^{d}
\end{array}\right.
$$

Electromagnetic Torque of the wind turbine is given as:

$$
C_{m}=\frac{a}{2}\left(P_{p}\left(\psi_{s p}^{d} I_{s p}^{q}-\psi_{s p}^{d}\right)+P_{0} L_{m}\left(I_{v}^{d} I_{r}^{q}-I_{u}^{q} I_{r}^{d}\right)\right)(3)
$$

\section{Field Oriented Control of BDFIG}

The surface orientation power machine has been selected so as to obtain a good decoupled control. [4]

$$
\left(\psi_{s p}^{d}=\psi_{s p}\right) \text { and }\left(\psi_{s s}^{q}=0\right) \text {. }
$$

The obtained control strategy for the BDFM resembles to the well-known stator field orientation control used in the(BDFIM).

By neglecting resistances of the stator phases the stator voltage will be expressed by:

$$
\left\{\begin{array}{l}
V_{s p}^{d}=0 \\
V_{s p}^{q}=V_{s p}
\end{array}\right.
$$

The stator active and reactive power can be written according to the stator currents as:

$$
\left\{\begin{array}{l}
P_{s p}=V_{s p}^{q}\left[-\delta_{4} \psi_{r}^{q}+\delta_{1} I_{s}^{q}\right] \\
Q_{s p}=V_{s p}^{q}\left[\delta_{5} \psi_{s p}^{d}-\delta_{4} \psi_{r}^{d}+\delta_{1} I_{s v}^{d}\right]
\end{array}\right.
$$

The stator active and reactive power and voltages are given by:

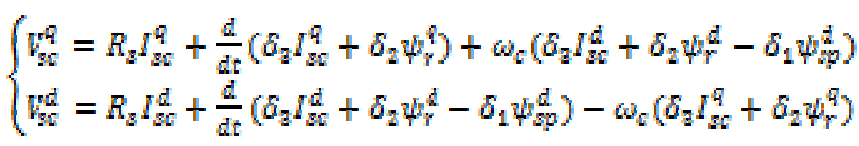


Where:

$\delta_{1}=\frac{L_{m c} L_{m p}}{L_{s p} L_{r}-L_{m p}^{2}}, \delta_{2}=\frac{L_{m c} L_{s p}}{L_{s p} L_{r}-L_{m p}^{2}}, \delta_{3}=L_{s c}-\frac{L_{m c}^{2} L_{s p}}{L_{s p} L_{r}-L_{m p}^{2}}, \delta_{4}=$ $\frac{L_{m p}}{L_{s p} L_{r}-L_{m p}^{2}}, \delta_{5}=\frac{L_{r}}{L_{s p} L_{r}-L_{m p}^{2}}$

The block-diagram representing the internal model of the system is presented in Figure 2. The input blocks relating $V_{s c}^{q}, V_{s c}^{d}$ represent the simplified stator converter model. Knowing equations (5) and (6), it is then possible to synthesize the regulators.

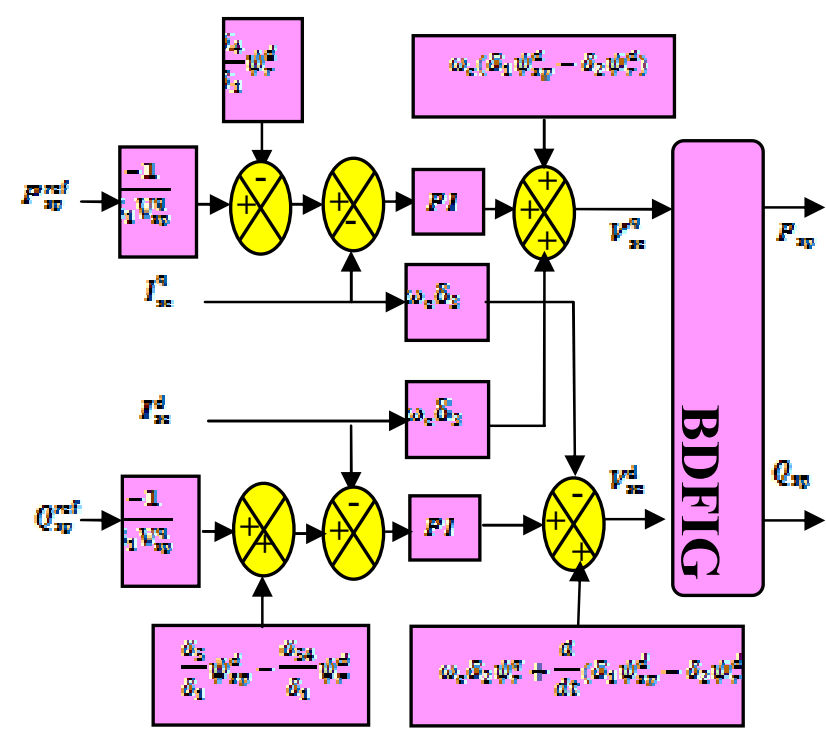

Figure.2. Block diagram of the power system

\section{III.1 Fuzzy Control}

Fuzzy controllers are non-conventional linear controllers. They can give satisfactory results if they are built correctly using the schema of the system operator. Their design is composed of: (1) determining the inputs, (2) establishing rules and (3) the method of calculation to convert the rules in a net output signal, known adefuzzification. First of all, the input index in this case is the error and the variance ratio. The error index is estimated and based on the net value the signal; it can be expressed in terms of degree of composition of fuzzy sets. The shape of fuzzy sets can be determined by the expert knowledge of the system. The following step is to build the fuzzy rules, again based on the expert knowledge of control problems, to accommodate all possible combinations of memberships [6].

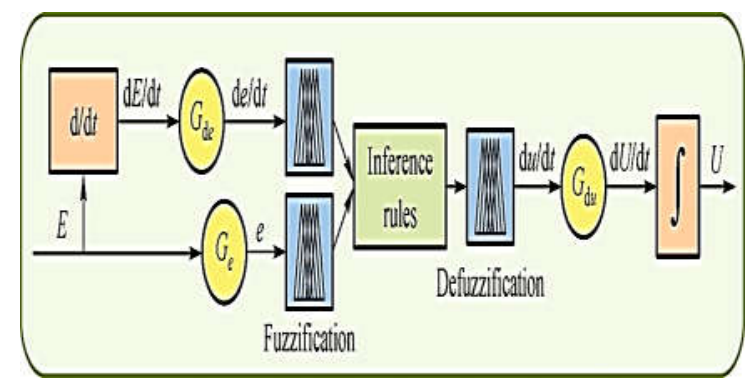

Figure.3. Structure of fuzzy logic controller
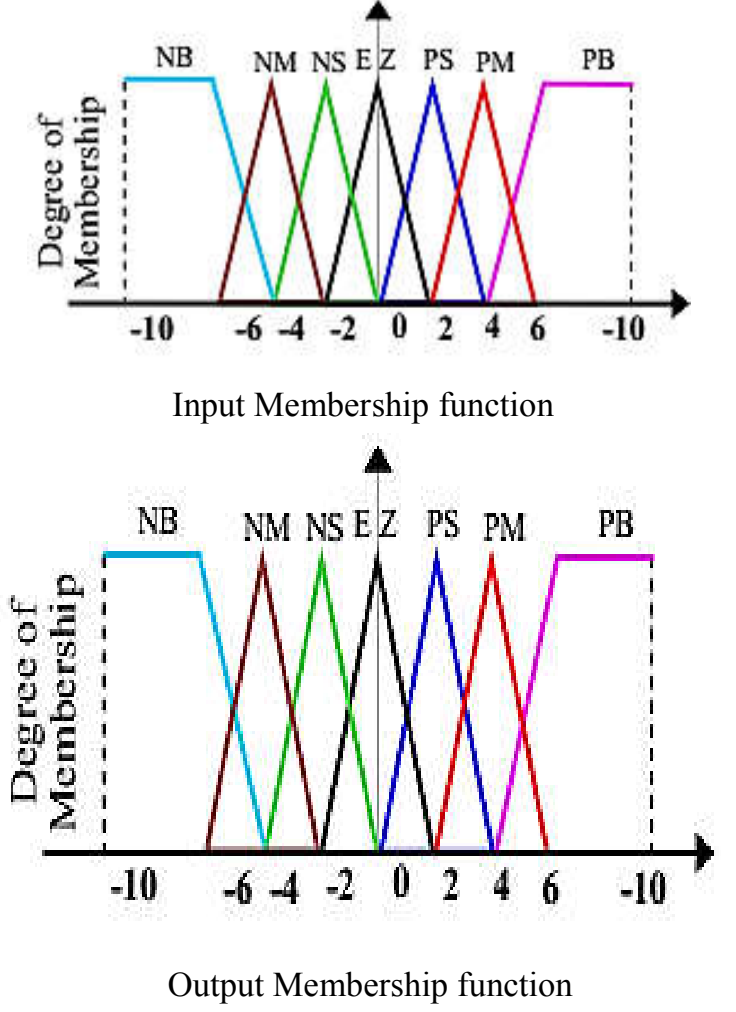

Figure.4. Membership functions for inputs and output

Table 1. Rule table of the fuzzy controller

\begin{tabular}{|l|l|l|l|l|l|}
\hline $\mathrm{E} / \Delta \mathrm{e}$ & $\mathrm{BN}$ & $\mathrm{SN}$ & $\mathrm{AZ}$ & $\mathrm{SP}$ & $\mathrm{BP}$ \\
\hline $\mathrm{BN}$ & $\mathrm{BN}$ & $\mathrm{BN}$ & $\mathrm{BN}$ & $\mathrm{BN}$ & $\mathrm{AZ}$ \\
\hline $\mathrm{SN}$ & $\mathrm{BN}$ & $\mathrm{SN}$ & $\mathrm{SN}$ & $\mathrm{AZ}$ & $\mathrm{SP}$ \\
\hline $\mathrm{AZ}$ & $\mathrm{SN}$ & $\mathrm{SN}$ & $\mathrm{AZ}$ & $\mathrm{SP}$ & $\mathrm{SP}$ \\
\hline $\mathrm{SP}$ & $\mathrm{SN}$ & $\mathrm{AZ}$ & $\mathrm{SP}$ & $\mathrm{SP}$ & $\mathrm{BP}$ \\
\hline $\mathrm{BP}$ & $\mathrm{AZ}$ & $\mathrm{SP}$ & $\mathrm{BP}$ & $\mathrm{BP}$ & $\mathrm{BP}$ \\
\hline
\end{tabular}




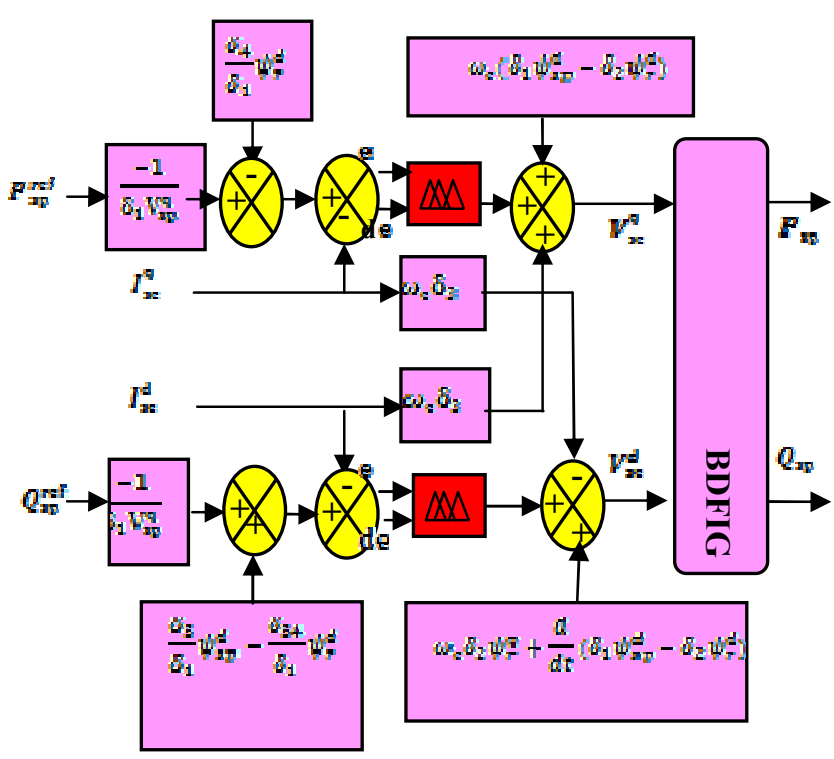

Figure.5. Block diagram of BDFIG Fuzzy control scheme

\section{III.2. Sliding Mode Control}

In order to improve and enhance the response of our system; we add another loop sliding mode. This type of control appeared for the first time in the Soviet Union during the sixties, it proved a great success in the recent years because it is easily used in industries.

This control is known by its robustness in the system. This control aims to force the system to reach a vicinity of the sliding surface and stay at this level [9]. So, we wanted to compare between these mode commands and another one to benefit from their advantage.

\section{III.3. Witching surface}

Switching function, the design of control system will be demonstrated for a following nonlinear system [8]:

$$
\dot{x}=f(x, t) \times B(x, t) \times u(x, t)
$$

Where: $x \in \mathbb{R}^{n}$ is the state vector, $u \in R^{n}$ is the control vector, $B(x, t) \in R^{n x m}$.

It's possible to define a set $\mathrm{S}$ of the state trajectories $\mathrm{x}$ such as:

$$
s=\{(x(t) \mid s(x, t)=0)\}
$$

The following two conditions have to be satisfied:

$$
s(x, t)=0, \dot{s}(x, t)=0
$$

The control law satisfies the precedent conditions is presented in the following form:

$$
\left\{\begin{array}{l}
U=U_{n}+U_{e q} \\
U_{n}=K \times \operatorname{sign}(s(x, t))
\end{array}\right.
$$

Where $U$ is the control vector, $U_{a q}$ is the equivalent control vector, is the switching part of the control (the correction factor), $\mathrm{k}$ is the controller gain. $U_{s q}$ can be obtained by considering the condition for the sliding regimen, $. s(x, t)=0$ The equivalent control keeps the state variable on sliding surfaces, once they reach it:

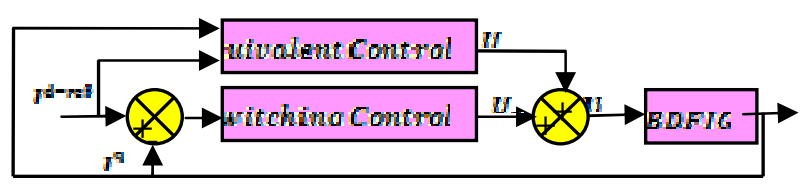

Figure.6. Sliding mode control Block

$$
\operatorname{sut}(s i x))=\left\{\begin{array}{l}
1 s i \quad s(x)>1 \\
-1 s i \quad s(x)<1 \\
0 x \quad \mid s(x) \leq 0
\end{array}\right.
$$

The sliding surface proposed by J.J. Slotine is used in this work:

$$
S(x)=\left(\frac{d}{d t}+\lambda\right)^{n-1} \times e
$$

$\lambda:$ is a positive coefficient,

$\theta=x_{d}-x$ is the error.

$x_{d}:$ is the desired state.

$\mathrm{n}$ : is the system order.

\section{III.4. Direct power control (DPC) with SMC of a BDFIG}

In this section, the sliding surfaces are designed based on the active and the reactive power references given in the Eq. (5). The objective of this design is to independently control the active and reactive generated powers converts.

\section{A-Choice of the sliding surfaces control}

The expressions of the stator voltages according to the stator currents:

$$
\left\{\begin{array}{l}
I_{s c}^{q}=\frac{1}{2_{s c}}\left[V_{s c}^{q}-R_{w} i_{s c}^{q}-L_{m g} i_{r}^{d}-\omega_{c}\left(L_{s} i_{s}^{d}+L_{m} i_{r}^{d}\right)\right] \\
I_{s c}^{d}=\frac{1}{L_{s c}}\left[V_{s c}^{d}-R_{s c} i_{s c}^{d}-L_{m p} i_{r}^{d}-\omega_{c}\left(L_{s c} i_{s c}^{q}+L_{m c} i_{r}^{q}\right)\right]
\end{array}\right.
$$

The surface of the control $I_{s c}$ current is defined by:

$\left\{\begin{array}{l}S\left(I_{s c}^{q}\right)=I_{s}^{q r e f}-I_{s c}^{q} \\ S\left(I_{s c}^{d}\right)=I_{s}^{d} r e f-I_{s}^{d}\end{array}\right.$

\section{B-Conditions of convergence of this control}

To guarantee the convergence of selected variables towards the references, the two slip surfaces need to be null as following

$$
\left\{\begin{array} { l } 
{ S ( I _ { s } ^ { q r e f } - I _ { s } ^ { q } ) = 0 } \\
{ S ( I _ { s } ^ { d } r g f - I _ { s } ^ { d } ) = 0 }
\end{array} \Rightarrow \left\{\begin{array}{l}
\frac{d}{d t}\left(I_{s}^{q r e f}-I_{s s}^{q}\right)=0 \\
\frac{d}{d t}\left(I_{s}^{d r e f}-I_{s u}^{d}\right)=0
\end{array}(15)\right.\right.
$$


The condition of a sliding mode control base on Lyapunov attractively $(s(x) s(x))<0$ )and the surface current time invariance $s(x)=0$

For $\mathrm{n}=1$, the surface of the current control can be set from the equation as follow

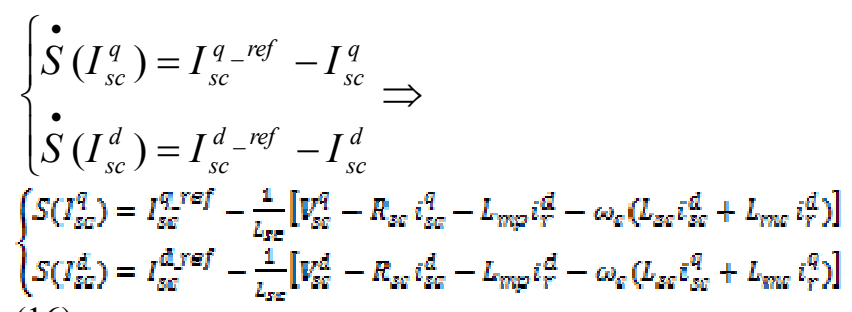
(16)

C- The control voltage and sign function law satisfy is presented in the following form

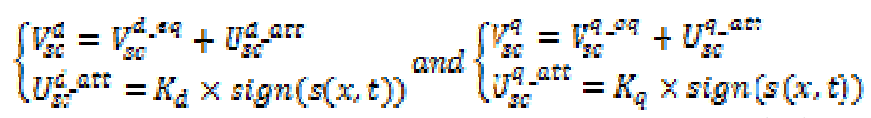

With:

$V_{s}^{d}, V_{s}^{q}$ are the control vectors relation.

$V_{s c}^{d_{-} e q}, V_{s c}^{q_{-}}{ }^{a q}$ are the equivalent control vectors relation.

$V_{s}^{d} a t t, V_{s}^{q} a t t$ are the switching control.

$K_{\mathrm{d},}, K_{\mathrm{q}}:$ are positive constant. by:

Finely the equivalent control voltage control is given

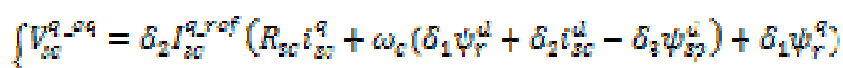

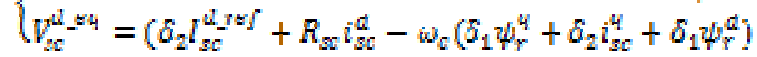

The BDFIG global sliding-mode control are presented in Figure 7

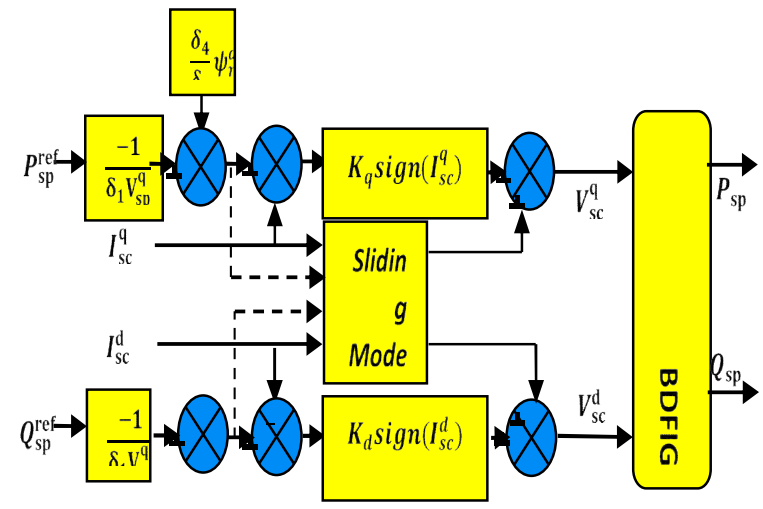

Figure.7. Block diagram of BDFIG Sliding Mode Control scheme

\section{Simulation Results}

Table 2 shows the electrical parameters of BDFIG

Table 2. The electrical parameters of BDFIG

\begin{tabular}{|l|l|l|l|}
\hline Rated voltage & $\mathrm{V}_{\mathrm{p}}=220 \mathrm{~V}$ & $\mathrm{P}_{\mathrm{c}}=3$ & \\
\hline Pole pairs number & $\mathrm{P}_{\mathrm{p}}=1$ & $\mathrm{R}_{\mathrm{c}}=1.079$ & \\
\hline Resistance $(\Omega)$ & $\mathrm{R}_{\mathrm{p}}=1.732$ & $\mathrm{I}_{\mathrm{p}}=121.7$ & $\mathrm{R}_{\mathrm{r}}=0.473$ \\
\hline $\begin{array}{l}\text { Self- } \\
\text { inductance }(\mathrm{mH})\end{array}$ & $\mathrm{I}_{\mathrm{p}}=714.8$ & $\mathrm{M}_{\mathrm{c}}=59.8$ & $\mathrm{~L}_{\mathrm{r}}=132.6$ \\
\hline $\begin{array}{l}\text { Mutual } \\
\text { inductance }(\mathrm{mH})\end{array}$ & $\mathrm{M}_{\mathrm{p}}=242.1$ & & \\
\hline Nominal power & $\mathrm{P}_{\mathrm{n}}=2.5 \mathrm{KW}$ & & \\
\hline $\begin{array}{l}\text { Synchronous } \\
\text { speed }\end{array}$ & $78.3 \mathrm{rad} / \mathrm{s}$ & & \\
\hline
\end{tabular}

\section{System results and discussions}

The results obtained are a comparison between two controls Fuzzy and sliding mode control, respectively organized according to the following figures.

The Active power curve in Figure 8 illustrates that The Fuzzy control which ensures high optimization of the extracted power and greatly reduces the fluctuation around optimal value, it can be also clearly seen that Fuzzy controller demonstrates more performance than sliding mode control.
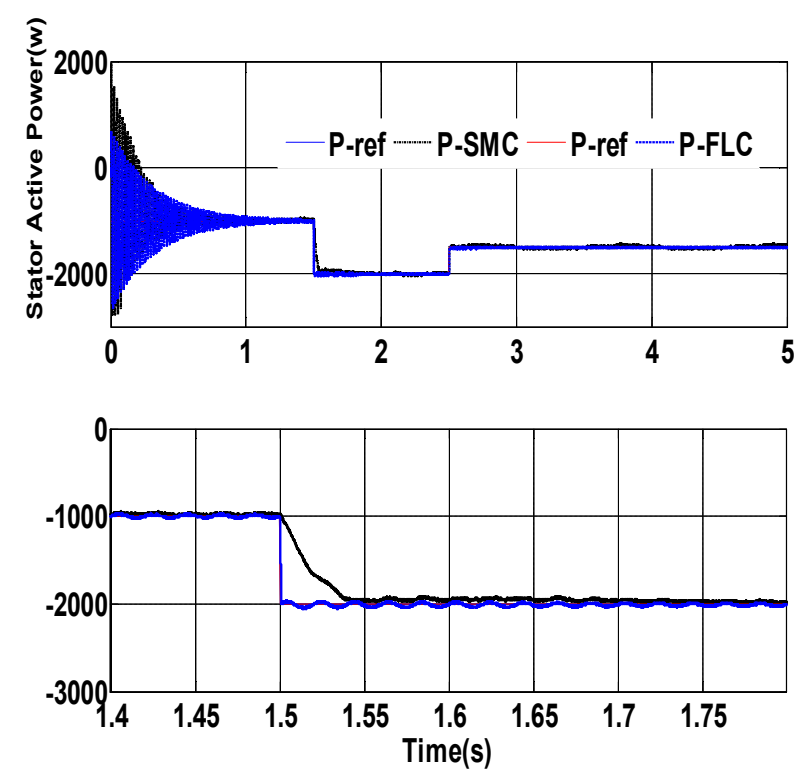

Figure.8. Active a power response of Stator (PW)

In the Figure 9, the Reactive power is set to (0VAR), it had been observed that the two controllers have similar results, but the problem of chattering is evident in sliding mode controller curve and proves that Fuzzy control is more robust and provides better performance. It can be 
observed that the stator voltage and current are in opposite phases Figure 10, which shows that the machine is operating in a generation mode $(\cos \varphi=-1)$. After seeing the good tracking of the proposed set-points illustrated in Figure 9, the robustness of the structure of control against the incertitude of parameters should be checked.
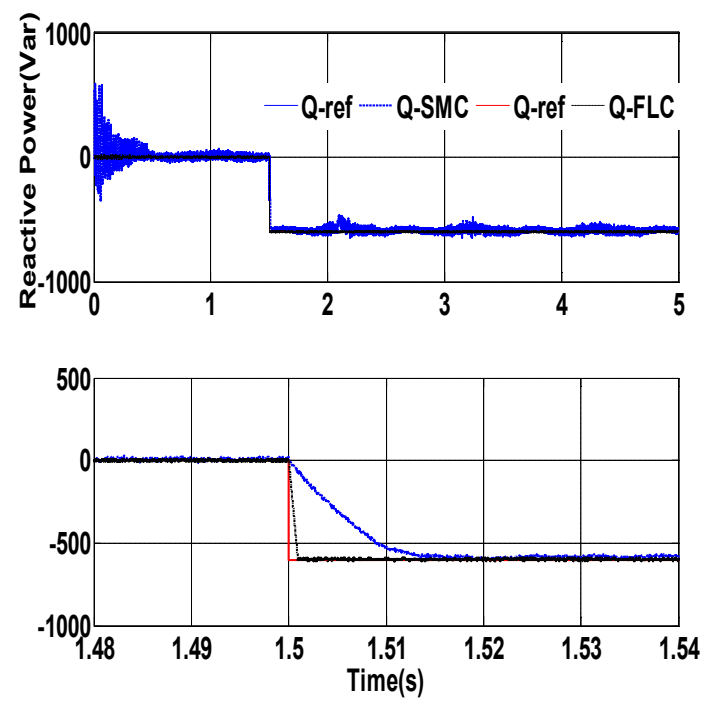

Figure.9. Reactive a power response of Stator (PW)

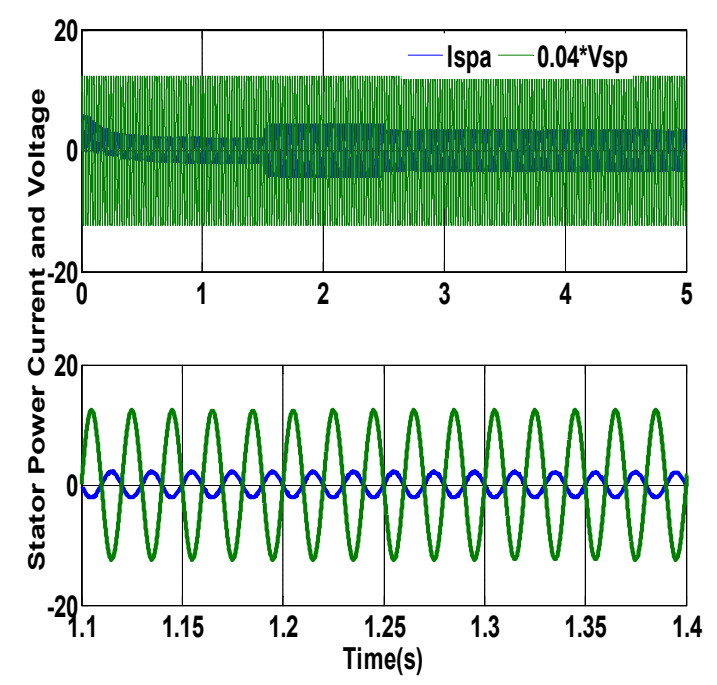

Figure.10. Stator (PW) voltage and current

Figure 11 illustrates the change of the variable speed in step form as follows when the speed is changed between 78 at the super-synchronized speed $86 \mathrm{rad} / \mathrm{s}$ to be reduced to $76 \mathrm{rad} / \mathrm{s}$.

We observed in the Figure 6 the active power is varied between $-1200 \mathrm{~W},-1800$ Wand in $-1800 \mathrm{~W}$ it remains respectively stable at $1.5 \mathrm{~s}$ and $3 \mathrm{~s}$ while the reactive power is fixed at 0 Var, from where the good tracking of the proposed control can be noted more clearly in the Figure 8 in comparison to the Figure 9.

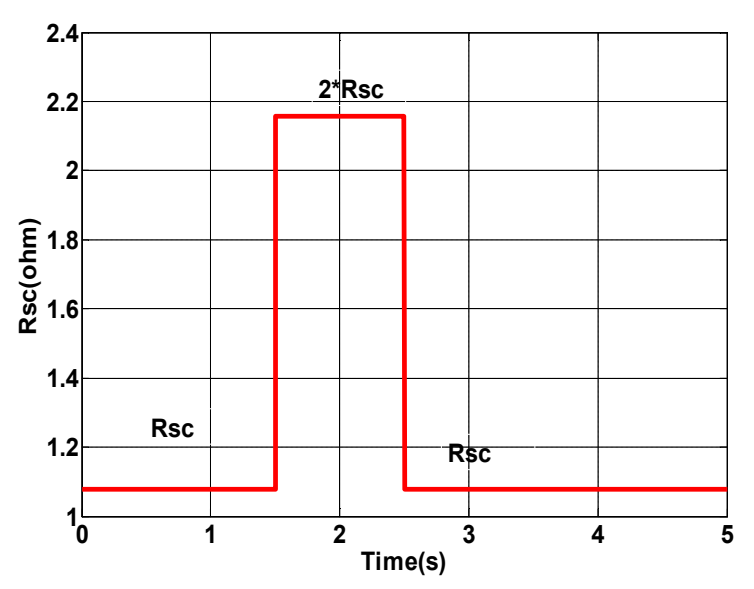

Figure.11. Parameter Variation

\section{Conclusion}

In this paper, we described two controls of the wind energy system equipped with Brushless Doubly Fed Induction Generator. At first, we proposed a mathematical model of the machine and generator in the form of the diagram. Then, we presented two strategies based on fuzzy and sliding mode control.

The machine obtained a good performance with the Fuzzy logic control even in the appearance of variations on target, and has high-power output efficiency. Finally, the fuzzy control has approved its robustness against speed variations in comparison with the sliding mode control that gives undesirable results.

\section{REFERENCES}

[1].REN21. (Jan. 2017). Renewables 2016: Global Status Report (GSR). [Online].Available:http://www.ren21.net

[2].C. Liu D. Xu and X. Zhang "Dynamic performance of brushless doubly-fed induction generator during symmetrical gridfault" Power Electronics and ECCE Asia (ICPE \& ECCE) 2011 IEEE 8th International.

[3].Yang, Jian, "Sensorless Control of Brushless Doubly Fed Induction Machine Using a Control Winding Current MRAS Observer", IEEE Transactions on Industrial Electronics, Vol. 66, N¹, 2019, pp. 728-738.

[4]. Cheng, Ming, Rensong Luo, and Xinchi Wei. "Design and Analysis of Current Control Methods for Brushless Doubly Fed Induction Machines." IEEE Transactions on Industrial Electronics, Vol. 66, N¹, 2019, pp. 717-727.

[5].Dong, Hao, "Research on Double-Fed Induction Generator Low Voltage Ride Through Based on Double Braking Resistors Using Fuzzy Control”. Energies Vol. 11, N5 2018, pp. 1155.

[6]. Zou, Yu, "A New Decoupled RotLin Motor with Fuzzy Sliding Mode Control”. IEEE Transactions on Magnetics (2018). 
[7]. R Cheikh, A Menacer, S. Drid, "Robust control based on the Lyapunov theory of a grid-connected doubly fed Induction generator". Frontiers in Energy, 2013, Vol. 7, №2, pp. 191-196.

[8 Y].Bekakra, D. Ben Attous, “ DFIG Sliding mode control fed by back to- back PWM converter with DC-link voltage control for variable speed wind turbine". Frontiers in Energy, 2014, Vol. 8, N³, pp.345-354

[9]. J. Lo, Y. Kuo, "Decoupled fuzzy sliding mode contro"l, IEEE Trans. Fuzzy Syst., Vol. 6, Nº. 3, 1998pp. 426-435. 